\title{
DARK Classics in Chemical Neuroscience: Salvinorin A
}

R. Bruno Hernández-Alvarado, Abraham Madariaga-Mazón, Alfredo Ortega, and Karina Martínez-Mayorga*

Universidad Nacional Autónoma de México, Instituto de Química, Ciudad Universitaria,

Ciudad de México, 04510 México

\section{Supplementary Information}


(1) Listos, J., Merska, A. and Fidecka, S. (2011) Pharmacological Activity of Salvinorin A, the Major Component of Salvia Divinorum. Pharmacol. Rep. 63, 1305-1309.

(2) Moniteur Belge - Belgisch Staatsblad

http://www.ejustice.just.fgov.be/cgi/article_body.pl?numac=2006023173\&caller=list\&pub_d ate $=2006-12-06 \&$ language $=$ fr (accessed Sept, 2020).

(3) Government of Canada, P. W. and G. S. C. (2015) Canada Gazette - Order Amending Schedule IV to the Controlled Drugs and Substances Act (Salvia Divinorum) http://gazette.gc.ca/rp-pr/p2/2015/2015-08-12/html/sor-dors209-eng.html (accessed Sept, 2020).

(4) Ministerio de Salud - República de Chile https://www.sag.gob.cl/sites/default/files/reg_ley_20_000_estupefacientes.pdf (accessed Sept, 2020).

(5) Popis opojnih droga, psihotropnih tvari i biljaka iz kojih se može dobiti opojna droga te tvari koje se mogu uporabiti za izdradu opojnih droga. https://narodnenovine.nn.hr/clanci/sluzbeni/2008_04_43_1436.html (accessed Sept, 2020).

(6) The Legal Status of Salvia divinorum http://www.sagewisdom.org/legalstatus.html (accessed Sept, 2020).

(7) Mahendran, R., Lim, H. A., Tan, J. Y. S., Chua, S. M. and Winslow, M. (2016) Salvia Divinorum: An Overview of the Usage, Misuse, and Addiction Processes. Asia-Pac. Psychiatry 8, 23-31.

(8) I. S. electronic Irish Statute Book (elSB)

http://www.irishstatutebook.ie/eli/2011/si/552/made/en/print (accessed Sept, 2020).

(9) Psychoactive Substances Bill 100-3 (2013), Government Bill - New Zealand Legislation

http://www.legislation.govt.nz/bill/government/2013/0100/latest/whole.htmI\#DLM5042926 (accessed Sept, 2020).

(10) Board Regulation. (2015) Dangerous Drugs Board https://www.ddb.gov.ph/images/Board_Regulation/2015/BD.REG3.15.pdf (accessed Sept, 2020).

(11) Participation, E. Psychoactive Substances Act 2016 https://www.legislation.gov.uk/ukpga/2016/2/contents (accessed Sept, 2020).

(12) European Drug Report, 2015 - European Drug Report. (2015) European Monitoring Centre on Drugs and Drug Addiction Report.

http://www.emcdda.europa.eu/publications/drug-profiles/salvia (accessed Sept, 2020)

(13) Griffin, O. H., Lee Miller, B. and Khey, D. N. (2008) Legally High? Legal

Considerations of Salvia Divinorum. J. Psychoactive Drugs 40, 183-191. 